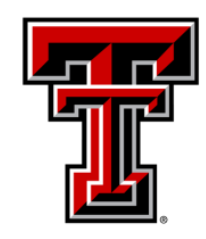

TEXAS TECH UNIVERSITY

Libraries"

\title{
THE IMPORTANCE OF UNDERSTANDING THE SHAPE OF DIVERSE ETHNIC FEMALE CONSUMERS FOR DEVELOPING JEANS SIZING SYSTEMS
}

\section{The Texas Tech community has made this publication openly available. Please share how this access benefits you. Your story matters to us.}

\begin{tabular}{|l|l|}
\hline Citation & $\begin{array}{l}\text { Shin, S.-J.H. and Istook, C.L. (2007), The importance of } \\
\text { understanding the shape of diverse ethnic female consumers for } \\
\text { developing jeans sizing systems. International Journal of Consumer } \\
\text { Studies, 31: 135-143. https://doi.org/10.1111/j.1470- } \\
\text { 6431.2006.00581.x }\end{array}$ \\
\hline Citable Link & $\underline{\text { http://hdl.handle.net/2346/2025 }}$ \\
\hline Terms of Use & $\underline{\text { CC-BY }}$ \\
\hline
\end{tabular}




\title{
The importance of understanding the shape of diverse ethnic female consumers for developing jeans sizing systems
}

\author{
Su-Jeong Hwang Shin ${ }^{1}$ and Cynthia L. Istook ${ }^{2}$ \\ ${ }^{1}$ Texas Tech University, Lubbock, TX, USA \\ ${ }^{2}$ North Carolina Sate University, Raleigh, NC, USA
}

\begin{abstract}
Keywords
Consumer ethnicity, apparel products, jeans, sizes, sizing systems, fit.

\section{Correspondence}

Sujeong Hwang Shin, Department of Design Apparel Design and Manufacturing, College of Human Sciences, Texas Tech University, Box 41162, Lubbock, TX 79409-1162, USA.

E-mail: su.hwang@ttu.edu
\end{abstract}

doi: 10.1111/j.1470-6431.2006.00581.x

\begin{abstract}
This study has been conducted to investigate the fit issues related to the current apparel pants and jeans sizing system for diverse consumers, identifying body shape differences among ethnic groups. A total of 1335 women in a certain size range (Misses figure type sizes 2-20) were selected in the study. A Misses figure type size category is commonly used for adult women of average proportion and height. First, the body dimension differences among ethnic groups were examined with a single factor analysis of variance. Second, the fit of pants and jeans for the diverse consumers within the same size category was examined with the current standard sizing system, ASTM D5585 for adult female Misses figure type sizes 2-20. Three cases were programmed within a database: When each consumer selects a size for a pair of jeans based on (1) waist size; (2) hip size; and (3) waist height (usually pants length). And last, the results were analysed with fit comparison plots. Current jean consumers are racially diversified in the US and globally as well. This study revealed that ethnic groups had different fit problems and significant body shape differences. Even within the same figure type size category, a variety of body dimensions existed in each ethnic group. According to the fit problem assessment in this study, consumers within the same body figure type size category could not find the right fit of the pants and jeans within the current sizing system. Half of the female consumers could not find a garment to fit based on waist height (pants length) because the current sizing systems overlooked the effect of diverse consumers. This study will be useful for standardizing organizations to modify current sizing systems for diverse ethnic consumer groups as a demographic factor so that apparel companies could provide better quality of fit for their consumers in the global and local market.
\end{abstract}

\section{Introduction}

Jeans and pants are popular apparel items for consumers. Women, especially, between the ages of 35 and 54 years spent $\$ 31$ billion to dress themselves in 2005, which was a $4.5 \%$ increase from the previous year. However, they were outspent by their daughters and younger sisters, ages 18-34 years, who shopped to the tune of $\$ 36.34$ billion during the same time period (Nachman, 2005). Jeans drove $75 \%$ of the denim market in 1998, accounting for the largest growth in women's denim apparel. Since women's jeans totalled 174 million pairs in 1997, with a value of $\$ 2.3$ billion, the quantities of women's jeans have increased (US Census Bureau, 1998). Jeans sales still remain mostly about the young, although older consumers are also adopting jeans.

Jeans are globally accepted as fashion items. Cotton Inc. (2005) provided evidence of global acceptance in its Global Lifestyle Monitor $^{\mathrm{TM}}$ survey in nine countries (Brazil, China, Colombia, Germany, India, Italy, Japan, the UK and Hong Kong), evaluating the ownership of denim apparel items by person and country. Denim ownership was highest in the US (13 items), Germany and Colombia (12.9 items) and lowest in India (3.1 items) and China (7.9 items). Casual dressing at work is now accepted at $58 \%$ of the offices of Global Monitor's worldwide respondents. In Colombia $78 \%$ of the offices allow casual dress. Although the US is not a premier production site for denim, it is a premier consumption market for Jeans (Allen and Huffman, 2005).

Modern jeans were invented by Levi Straus for hard-working men, but today wearing stylish jeans has become a fashion trend. Currently popular brands include Gap, Guess, True Religion, Seven For All Mankind, Earl Jean, Citizens of Humanity, Notify, James Jeans and AG Jeans. Levi's is also quite strong in Europe. Over the decades, styles have noticeably changed in jeans with a tighter fit and a lowered waistline placement. Growing jeans fashion trends have caused changes in apparel production and consumption. Premium denim, loosely defined as a pair of jeans selling as high as $\$ 70$ or more by the Monitor ${ }^{\mathrm{TM}}$ survey (Cotton 
Inc., 2005), is considered a 'must-have' for young female consumers. From 1998 to 2004, the percentage of women who would pay more than $\$ 70$ for a pair of good fitting jeans increased from $2 \%$ to $10 \%$ among 16 - to 19 -year-olds and from $3 \%$ to $12 \%$ among 20 to 24-year-olds (Cotton Inc., 2005). Fit is the most concern for two reasons: comfort and vanity (Strategic direction, 2005). Both are equally important and a great fit helps create confidence.

The demands for good fitting jeans drive many apparel companies to mass production of individually customized goods and services (Pine, 1993). Consumers are willing to pay more and willing to wait for the customized products. For instance, chino and jeans sales on Lands' End's website are now mass customized garments that have more pants fabric options and styles (Lands' End Inc. 2006). However, often consumers are still not satisfied with their purchases even after they have tried on multiple jeans to find an appropriate size and style.

Goldsberry et al. (1996) found that $69 \%$ of over 4000 female respondents were dissatisfied with fit. According to Kurt Salmon Associates Consumer Outlook, 59\% of US shoppers claimed inconsistent fit within one brand, and 57\% stated fit problems with standard sizes (Intellifit Corp, 2003). As a result, $40 \%$ of the purchased clothing is returned and $28 \%$ of consumers are reluctant to order from catalogues because of their concern about getting the right size (Telmat Industrie, 2002). These fit problems are associated with current sizing systems that overlook the diverse ethnicity that encompasses the full range of variation in body shapes existing in the population.

A sizing system includes a range of sizes based on graduations of dimensions for a body type. Apparel companies identify body types that are representative of their target customer and develop what they perceive to be appropriate proportions for each size and graduation between sizes (Glock and Kunz, 2005). Size labelling suggests to consumers the suitability of a garment for their body dimensions. Sizes are grouped together into following size classification according to gender, age and body type of consumers: Petite, Junior, Misses and Plus sizes (Tigert et al., 1996). For example, the Misses size designation was originally designed to fit the adult woman of average proportion and average height. They are also commonly referred to as missy sizes (Brown and Rice, 2001). The ASTM (2004) (American Standard Testing and Material) D5585 standard suggests Misses sizes as even numbers from 2 to 20 .

According to research conducted in the Chicago market during the 1990s, half of the female customers' body types were Misses sizes $(55 \%)$ and the remainder were Plus sizes (23\%), Petite sizes (18\%) and Junior sizes (8\%) (Tigert et al., 1996). However, several body types have not been well served by the apparel industry or considered for diverse ethnic consumers. For example, Fu (2004) studied body shapes in overweight Plus-sized female figures and found that they were shorter and fell into a Petite size category. Previous research (Ashdown, 1997; Anderson et al., 1998; Hwang and Istook, 2001; Jo et al., 2003) indicated that problems with the fit of women's apparel are based on outdated body measurement data and population averages.

Sizing systems around the world have been created using a variety of schemes from elaborate statistical methods to trial and error (Ashdown, 1997). The goal of any sizing system is to choose key body dimensions that will allow the division of the population into specific size groupings. Ultimately, the hope is that the group- ings will be developed to create the least number of sizes necessary to fit almost everyone in the population.

Although sizing systems around the world vary greatly, all are based on one key dimension that is used to define the sizes within the system. This dimension (such as waist) is generally distributed evenly across the system, in an attempt to cover the broadest range of measurements. For example, the waist measures from sizes 210 are 1 " apart, sizes $12-16$ are usually $1 \frac{1}{2} 2^{\prime \prime}$ apart and sizes 18 and up are 2 " apart. These ranges were developed to make the growth between sizes easy for manufacturers of ready-to-wear garments to manage. The remaining measurements that are required for a sizing system have been derived using regression statistics and averages related to the original key dimension. For example, the second most important dimension for design of a pair of pants is generally the hip measurement. Using the 1939 study (which has been the basis of all US sizing systems) the hips were generally about $10^{\prime \prime}$ bigger than the waist (given the fact that women at the time wore girdles and other body shaping apparel) creating basically an hourglass shape. The hip measurements for the system then increased in size in exactly the same proportion as the waist measurements. Length and height measurements increase in the same way, although with smaller proportions.

This method of size creation is clean and easy for manufacturers to use. Garment patterns from one size to the next fit nicely in a nest, and errors are easy to spot. Unfortunately, each of the sizing systems that have been developed has been based on the same assumption that the hips are generally 9" or so larger than the waist (the hourglass look) and all are generally ranged evenly from one size to the next. There are a multitude of problems related to this methodology. First, the number of people who currently have that 'hourglass' shape is significantly different than it might have been in 1939. Second, the even growth between all sizes is not logical, although it might be easier to accomplish. For example, a women $5^{\prime} 7^{\prime \prime}$ with an inseam measurement of $30^{\prime \prime}$ generally does not get any taller as she gets bigger (as our sizing systems indicate) and usually do not add weight evenly across all body areas. Third, regardless of the fact that women have complained of fit problems since the inception of standards in 1958, changes to the systems have actually reduced fit opportunities for these women rather than increasing them. CS215-58 (the standard originally developed from the 1939 study) had 36 different size ranges. The four classifications of women included 'Misses', 'Women's', 'Half-Sizes' and 'Juniors'. Three height groups were recognized as 'Tall', 'Regular' and 'Short'. Three hip types were recognized as 'Slender', 'Average' and 'Full' (Simmons, 2002).

Recognizing fit problems, researchers and apparel manufactures are developing apparel sizing systems to provide customer's needs for better fitting garments. Body shape analysis is the theory for the development of apparel sizing. In the theory, as it is currently implemented, apparel sizing is based on averaged anthropometric body measurements that must fit many body shapes within a size range (Connell et al., 2003). The Body Shape Analysis Scale (BSAS@) was developed in a National Textile Center project (Connell et al., 2003) to evaluate a complex set of body shape variations. Alexander et al. (2003) analysed a data set of 529 body scans using the BSAS $\odot$ to define whole and component body shapes of women. The shape analysis showed that the conventional hourglass body shape was present in only $33.6 \%$ of the women subjects (Alexander et al., 2003). 
The shape identification software, Female Figure Identification Technique $($ FFIT), was developed to analyse current female body shapes so that more correct sizing systems could be developed (Simmons et al., 2004). Using SizeUSA data and the FFIT software, Istook (2006) determined that approximately $46 \%$ of women were classified as rectangular, in which the bust and the hips are generally the same size, and the waist is less than nine inches smaller than the hips or the bust.

Current mass production and customization trends force apparel manufacturers to offer a range of selections for apparel items so that the customer can choose style and fit options. Over the decades, jeans' styles for Misses figure types have noticeably changed with a lowered waistline placement and a curved hipline. Certain jeans manufacturers have attempted to provide a variety of garments to fit the differently shaped women by adjusting the measurements in certain locations in the jeans. Style numbers then become representations of different fits, although the size numbers used to define the garments remains the same. Contrary to the standard development described earlier, the measurements that define a pair of jeans at specific points in one style may have absolutely no relationship to the measures that define another style of jeans in the same size. The significant differences in the fit of jeans of the same defined size appear to have no relationship to body measurement data that describe the current US population. It is important to understand current Misses figure body types to provide certain styles with correct fit.

The theory of body shapes for developing Misses sizing systems was proposed to the ASTM D13.55 standards committee; however, no standards were developed to accommodate the various body types. The current ASTM standard sizes were developed from body measurements used currently by apparel manufacturers and retail organizations and from anthropometric surveys conducted by the US Army (Gordon et al., 1988, p. 2) and by the US Navy (Mellian et al., 1990; Robinette et al., 1990). In the ASTM D5585-04, it says 'It is important to note that the body measurements herein have been derived from designer experience and market observations and crosschecked with available databases in the attempt to identify current customer characteristics and changing proportions and not from new nationwide anthropometric research.' The way it is currently used by jeans manufacturers has not successfully accommodated various body types. The jeans manufacturers in the US still use sizing systems that are based on the hourglass figure or pear shapes which are not representative of the majority of US women.

Diverse ethnic consumers might have different types of fit problems because the US population is becoming more ethnically diverse. The US immigrant population grew rapidly during the 1990s and the foreign-born population grew by $57 \%$ during the decade nationwide (Urban Institute Immigration Studies Program, 2002). According to Census Bureau in 2001, there were 31 million immigrants living in the country, representing $11 \%$ of the population (US Census Bureau, 2001). This indicates that the influence of ethnicity and diversity in the provision and consumption of consumer goods is truly both a US and a global phenomenon.

Vrontis and Vronti (2004), in a case study of Levi's international marketing investigation, indicated the importance of understanding ethnicity by describing seven factors that could influence their decision to make global standardization or international adaptation: Socio-cultural, Legal, Physical/environmental, Tech- nological, Demographic, Competition, and Economics. Two of the factors, socio-cultural and demographic, are related to fit and size issues.

Global fit vs. local fit is an important issue for a global business like Levi Strauss that aims to benefit from economies of scale and guarantees of quality that stem from worldwide advertising and standardized products (Vrontis and Vronti, 2004). In a study of body cathexis and satisfaction with fit of apparel, LaBat and DeLong (1990) emphasized that each manufacturer must successfully interpret body measurements and produce apparel that satisfies their target customer's fit. In other research, Kim and Kim (2005) provided an insight into developing different marketing strategies according to ethnicity.

Although researchers have assessed international marketing for jeans and the body shape analysis for the theory of developing current sizing systems, little research to date has assessed current sizing systems based on diverse ethnicity. Therefore, the purpose of this study was to identify body shape differences among ethnic groups and to investigate current apparel pants/jeans sizing system problems for diverse consumers. This study provides the underpinning that would allow researchers and apparel manufactures to understand the theoretical issues of diverse body shapes for the development of apparel jean's sizing systems.

\section{Methodology}

\section{Data collection and sample}

The SizeUSA National Sizing Survey was conducted by [TC $]^{2}$ (Textile/Clothing Technology Corporation, Cary, NC, US, nonprofit organization) between 2002 and 2003 in the US, and the survey data were used in this study. A $[\mathrm{TC}]^{2}$ body scanning system was used for scanning and measuring subjects' body dimensions of various demographic dimensions during the sizing survey. As this research purpose was to identify current women's apparel, especially, pants/jeans sizing problems for diverse ethnic groups, women were selected within a same size category and they were divided into five different ethnic groups. In this study, a Misses figure type size category was selected for the same size category because it is commonly used for adult woman of average proportion and average height.

A total of 1335 of 6310 women answered that they wear Misses size jeans. Table 1 shows the subjects' ethnicities and ages. The majority was Caucasian people $(62.92 \%)$, with the remainder being African-American, Hispanic, Mexican, Asian and others. Ages of the respondents were from 18 to 65 years old.

Table 1 Sample's ethnicity and ages who wear Misses sizes

\begin{tabular}{lclc}
\hline Ethnics & $n(\%)$ & Age (year) & $n(\%)$ \\
\hline Caucasian people & $840(62.92)$ & $18-25$ & $345(25.84)$ \\
African-American & $243(18.2)$ & $26-35$ & $298(22.32)$ \\
Hispanic & $47(3.52)$ & $36-45$ & $253(18.95)$ \\
Mexican & $71(5.32)$ & $46-55$ & $251(18.8)$ \\
Asian & $71(5.32)$ & $56-65$ & $140(10.49)$ \\
Others & $63(4.72)$ & $66+$ & $48(3.6)$ \\
Total & $1335(100)$ & Total & $1335(100)$ \\
\hline
\end{tabular}


Table 2 Misses size jean consumers in each ethnic and age group

\begin{tabular}{|c|c|c|c|c|c|}
\hline Ethnics & $n$ & $\begin{array}{l}\% \text { of jean consumers in } \\
\text { each ethnic group }\end{array}$ & Age (year) & $n$ & $\begin{array}{l}\% \text { of jean consumers in } \\
\text { each age group }\end{array}$ \\
\hline Caucasian people & 737 & 88 & $18-25$ & 332 & 96.2 \\
\hline African-American & 210 & 86 & $26-35$ & 258 & 86.6 \\
\hline Hispanic & 36 & 75 & $36-45$ & 222 & 87.7 \\
\hline Mexican & 60 & 85 & 46-55 & 213 & 84.9 \\
\hline Asian & 62 & 87 & $56-65$ & 101 & 72.1 \\
\hline Others & 56 & 84 & $66+$ & 35 & 72.9 \\
\hline Total & 1161 & 87 & Total & 1161 & 87 \\
\hline
\end{tabular}

Table 2 shows the Misses size jean consumer in each ethnic and age group. Overall, a total of $87 \%$ of Misses size consumers enjoyed jeans in the Misses size category. Not surprisingly, $96.2 \%$ of the jean consumers were in the 18-25 years age group; however, all ethnic groups and age groups were fairly equal in percentages.

\section{Data statistical analysis procedure}

First, it was necessary to examine if the respondents had the same body figure type with the following null hypotheses, because diverse ethnic groups exist in the Misses figure type size category:

Ho: There will be no body dimension differences among ethnic groups.

Ha: There will be body dimension differences among ethnic groups.

Body dimension differences were examined in the waist, hips, thigh maximum circumference, crotch length, crotch height (inseam), waist height (pants length, outseam); all are measures that impact the fit of a pair of pants/jeans. The null hypotheses were tested with a single factor analysis of variance (ANOVA) with a $5 \%$ level of significance. After the ANOVAs were tested in each ethnic group, Bonferroni's multiple comparisons with significance level set at $\alpha=0.05$ was used to find the difference between ethnic groups.

Second, pants/jeans fit was examined to identify if diverse consumers within the same size category could find the right size and fit of jeans with the current ASTM standard sizing system. For the analysis, the following three cases were programmed into a database application using the collected data from the survey:

1 When each consumer finds a pair of jeans based on waist sizes. 2 When each consumer finds a pair of jeans based on hip sizes.

3 When each consumer finds a pair of jeans based on waist height (usually pants outseam length).

Each consumer's body dimensions were matched with sizes in the standard ASTM D5585 for Adult Female Misses Figure Type Sizes 2-20. Table 3 shows the waist and hip measurements in the standard sizes 2-20 and the intervals between sizes that were used for defining a fit in this analysis.

For example, if the subject's hip girth was 38.7 inches, her pants size could be size 10 . If she tried on size 8 for 38 inches, the hips would not be considered within the size range for best fit. Therefore, the size intervals were defined with following simple query languages in this case: WHERE (((ASTM_size.[Body Type]) = 'Missy 5585') AND ((USfemale.Hips) < [ASTM_size.Hips]) AND $(([$ ASTM_size.Hips] $])<([$ USfemale.Hips] + 1)) $)$. And last,
Table 3 Waist and Hips measurements and size intervals in Misses figure type sizes 2-20

\begin{tabular}{cllll}
\hline Sizes & Waist & $\begin{array}{l}\text { Waist size } \\
\text { interval }\end{array}$ & Hips & $\begin{array}{l}\text { Hip size } \\
\text { interval }\end{array}$ \\
\hline 2 & 24 & -1 & 35 & -1 \\
4 & 25 & -1 & 36 & -1 \\
6 & 26 & -1 & 37 & -1 \\
8 & 27 & -1 & 38 & -1 \\
10 & 28 & -1 & 39 & -1 \\
12 & 30 & -2 & 40 & -1.5 \\
14 & 31 & -2 & 42 & -1.5 \\
16 & 33 & -2 & 43 & -1.5 \\
18 & 35 & -2 & 45 & -2 \\
20 & 37 & -2 & 47 & -2 \\
\hline
\end{tabular}

the results were analysed in graphical plots that displayed comparison subject's body dimensions to the Misses figure type standard sizes.

\section{Results and discussion}

\section{Diverse ethnicity as a demographic factor}

Diverse consumers' body dimension categories were analysed using single factor ANOVA to identify fit problems in each ethnic group. Table 4 shows the results from ANOVA among diverse ethnic consumer groups. The asterisk has been placed to indicate that these pairs show statistically significant differences at the $95.0 \%$ confidence level.

The following body dimensions were significantly different by rejecting the null hypotheses $(P>0.05)$ : height, waist, hips, thigh, crotch length, crotch height (inseam), waist height (pants outseam length). As there were significant body dimension differences among groups, Bonferroni multiple comparisons with significance level set at $\alpha=0.05$ were used to determine which means were determined to be significantly different.

Table 5 shows the multiple comparison results. Asians and African-Americans were statistically significantly different at the 95\% confidence level in all body dimension categories. AfricanAmericans were also significantly different from Caucasian people in lower body dimension categories (waist, hips, thigh, crotch length, crotch height and waist height). Generally, in this study, Asians showed the smallest body dimensions (Waist mean = $31.48^{\prime \prime}$, Hips mean $=39.52^{\prime \prime}$, Thigh mean $=22.86^{\prime \prime}$, Crotch length mean $=26.52^{\prime \prime}$, Crotch height mean $=28.48^{\prime \prime}$, Waist height 


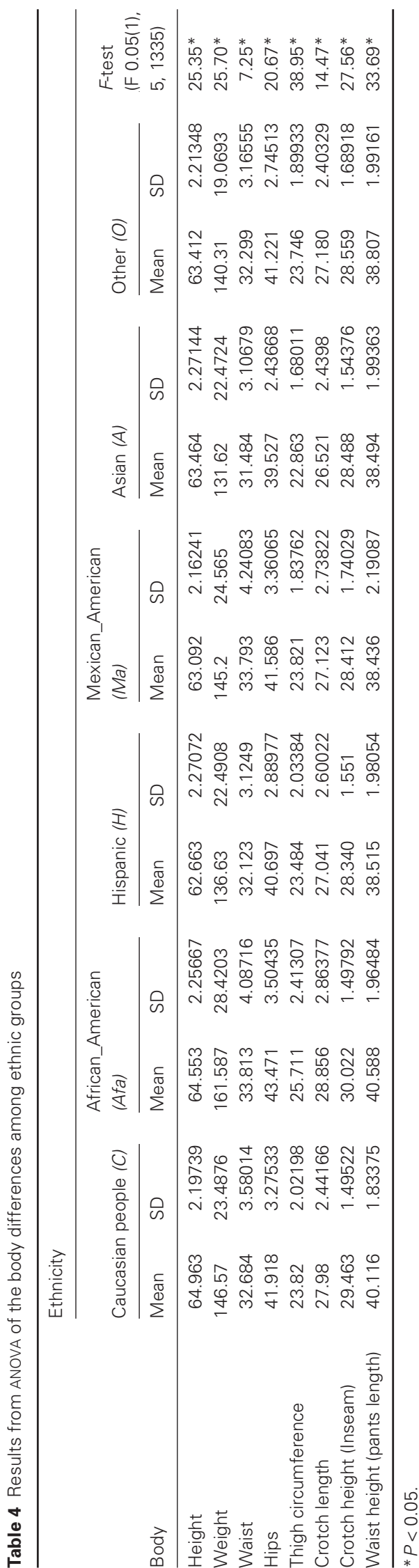

mean $\left.=38.49^{\prime \prime}\right)$ while African-Americans showed the largest body dimensions (Waist mean $=33$. 81", Hips mean $=43.47^{\prime \prime}$, Thigh mean $=25.71^{\prime \prime}$, Crotch length mean $=28.85^{\prime \prime}$, Crotch height mean $=30.02^{\prime \prime}$, Waist height mean $=40.58^{\prime \prime}$ ).

As shown in Table 5, Hispanics and Mexican-Americans were not statistically different in the lower body dimension categories. Asians were not statistically different from Hispanics but different from Mexican-Americans in the waist (mean differences = $-2.30915^{\prime \prime}$ ) and hip categories (mean differences $=-2.0587^{\prime \prime}$ ).

Figure 1 shows the comparison between mean body dimension values among ethnic groups. As shown in Fig. 1, MexicanAmericans had larger waists and hips than Asian and Hispanics. The Mexican-American's waist dimension was similar to the African-Americans' while the Hispanic's waist and hips were similar to the Asians'. This indicates that the Hispanics' lower body dimensions were very similar to Asians'. The AfricanAmerican group was significantly different from all other groups in the thigh dimension and crotch length categories, showing a larger thigh and longer crotch length (see Fig. 1).

The Mexican-American and Hispanic groups were not statistically different from the White group in the following lower body dimensions: waist, hips, thigh and crotch length. However, they were statistically different in the crotch height (Mean differences $=-1.05151^{\prime \prime}$ and $-1.1234^{\prime \prime}$ ) and waist height (Mean differences $=-1.68073^{\prime \prime}$ and $\left.-1.60081^{\prime \prime}\right)$ categories as shown in Table 5. Both Mexican-American and Hispanic groups showed shorter crotch height and waist height than the White group's average as shown in Fig. 1. Mexican-American and Hispanic's crotch height (inseam length) and waist heights (pants length) were similar to Asian's.

These results indicate that each ethnic group has unique body dimensions. Therefore, diverse consumers in the global and the US local market could not fit within one figure body type size indicating that a real challenge exists with the issue of fit among diverse ethnic groups.

\section{Fit problem assessment with a current sizing system}

As body dimension differences were found among ethnic groups from statistical analysis, pants/jeans fit was examined if diverse consumers within a same size category could find their sizes with a current standard sizing system by testing when each consumer finds a pair of jeans base on three cases: (1) waist sizes; (2) hip sizes; and (3) waist height (pants length).

Table 6 shows the results of finding jeans fit based on the three different cases. The noticeable results were in waist height (pants length), showing that $49.29 \%$ of subjects could not find right pants sizes within the standard sizing system. It should be noted that most women's apparel companies do not provide various pants lengths. For example, women's jeans sizes are based on the waist size with only three choices such as short, regular, or long while men's pants sizes are based on waist sizes and as wide range pants length choices as well (e.g. 34/30, 34/32 and 34/36).

Waist sizes are commonly asked for pants/jeans in a retail store, but as shown in Table 6 and $15.88 \%$ of subjects' waists would not be within the current size range. When hip sizes and waist sizes were compared to find jeans fit, $92.21 \%$ of subjects could find their hip sizes within the standard size ranges. 
Table 5 Multiple comparison results of the body dimension differences among ethnic groups

\begin{tabular}{|c|c|c|c|c|c|c|}
\hline \multirow[b]{2}{*}{ Contrast ethnic groups } & \multicolumn{6}{|c|}{ Body dimensions } \\
\hline & Waist & Hips & Thigh & Crotch length & Crotch height & Waist height \\
\hline Asian: African American & $-2.32949 *$ & $-3.94368^{*}$ & $-2.84779^{*}$ & $-2.33504^{*}$ & $-1.53416^{*}$ & $-2.09404^{*}$ \\
\hline Asian: Hispanic & -0.639923 & -1.17026 & -0.621282 & -0.52024 & 0.147576 & -0.0212245 \\
\hline Asian: Mexican American & $-2.30915^{*}$ & $-2.0587^{*}$ & -0.957876 & -0.601881 & 0.0756874 & 0.0586947 \\
\hline Asian: Other & -0.815777 & $-1.69458^{*}$ & -0.883017 & -0.659401 & -0.0719356 & -0.312745 \\
\hline Asian: Caucasian people & -1.20082 & $-2.39152^{*}$ & $-0.956628^{*}$ & $-1.46366^{*}$ & $-0.975824^{*}$ & $-1.62203^{*}$ \\
\hline African American: Hispanic & 1.68957 & $2.77342^{*}$ & $2.22651^{*}$ & $1.8148^{*}$ & $1.68173^{*}$ & $2.07281^{*}$ \\
\hline African American: Mexican American & 0.0203457 & $1.88498^{*}$ & $1.88991^{*}$ & $1.73316^{*}$ & $1.60984^{*}$ & $2.15273^{*}$ \\
\hline African American: Other & 1.51372 & $2.2491^{*}$ & $1.96477^{*}$ & $1.67564^{*}$ & $1.46222^{*}$ & $1.78129^{*}$ \\
\hline African American: Caucasian people & $1.12868 *$ & $1.55216^{*}$ & $1.89116^{*}$ & $0.871378^{*}$ & $0.558332^{*}$ & $0.472005^{*}$ \\
\hline Hispanic: Mexican American & -1.66922 & -0.88844 & -0.336595 & -0.0816406 & -0.0718885 & 0.0799192 \\
\hline Hispanic: Other & -0.175854 & -0.52432 & -0.261735 & -0.139161 & -0.219512 & -0.291521 \\
\hline Hispanic: Caucasian people & -0.560892 & -1.22127 & -0.335346 & -0.943421 & $-1.1234^{*}$ & $-1.60081^{*}$ \\
\hline Mexican American: Other & 1.49337 & 0.36412 & 0.0748594 & -0.05752 & -0.147623 & -0.37144 \\
\hline Mexican American: Caucasian people & 1.10833 & -0.332825 & 0.00124881 & -0.86178 & $-1.05151^{*}$ & $-1.68073^{*}$ \\
\hline Caucasian people: Other & -0.385038 & -0.696945 & -0.0736106 & -0.80426 & $-0.903889 *$ & $-1.30929^{*}$ \\
\hline
\end{tabular}

*The asterisk denotes a statistically significant difference in 95.0\% confidence level.

Table 6 Results of finding jeans fit based on waist sizes, hips sizes and pants length

\begin{tabular}{|c|c|c|c|c|c|c|}
\hline \multirow[b]{2}{*}{ Size } & \multicolumn{2}{|l|}{ Waist } & \multicolumn{2}{|l|}{ Hips } & \multicolumn{2}{|c|}{ Waist height (pants length) } \\
\hline & $n$ & $\%$ of female & $n$ & $\%$ of female & $n$ & $\%$ of female \\
\hline 2 & 0 & 0 & 3 & 0.22 & 73 & 5.47 \\
\hline 4 & 2 & 0.15 & 3 & 0.22 & 57 & 4.27 \\
\hline 6 & 11 & 0.82 & 28 & 2.10 & 78 & 5.84 \\
\hline 8 & 24 & 1.80 & 57 & 4.27 & 73 & 5.47 \\
\hline 10 & 54 & 4.04 & 98 & 7.34 & 69 & 5.17 \\
\hline 12 & 151 & 11.31 & 185 & 13.86 & 75 & 5.62 \\
\hline 14 & 218 & 16.33 & 277 & 20.75 & 65 & 4.87 \\
\hline 16 & 227 & 17.00 & 235 & 17.60 & 55 & 4.12 \\
\hline 18 & 243 & 18.20 & 207 & 15.51 & 59 & 4.42 \\
\hline 20 & 193 & 14.46 & 138 & 10.34 & 54 & 4.04 \\
\hline Total of people found sizes & 1123 & 84.12 & 1231 & 92.21 & 658 & 49.29 \\
\hline Total of people could not find sizes & 212 & 15.88 & 104 & 7.79 & 677 & 51 \\
\hline
\end{tabular}

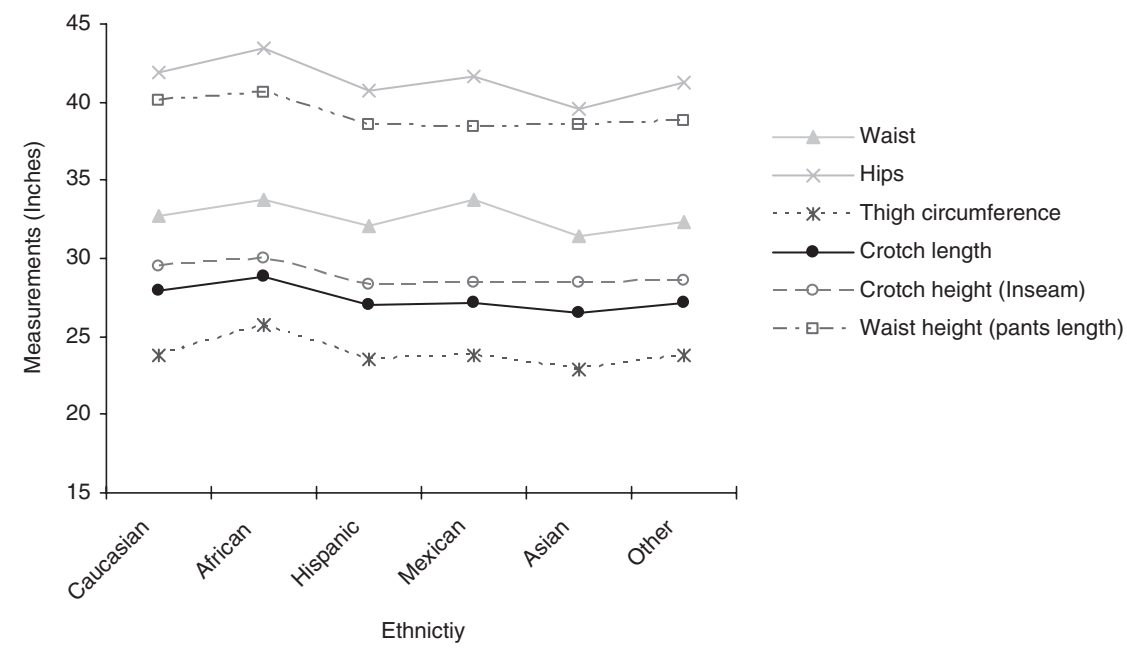

Figure 1 Mean value comparison in each ethnic group. 
Table 7 shows different fit problems of waist and hips among ethnic groups. Most subjects' waists were larger than size 20, and $25.35 \%$ of Mexican-American and $21.81 \%$ of African-American had waist measurements larger than 20". The African-American group shows larger hip sizes that could not fit within the current standard size ranges. On the other hand, Caucasian people, Asian and Hispanic did not show many fit problems with waist and hip sizes.

Table 7 Different fit problems of waist and hips among ethnic groups

\begin{tabular}{|c|c|c|c|c|c|c|c|}
\hline \multirow{3}{*}{\multicolumn{2}{|c|}{ Ethnicity }} & \multicolumn{6}{|c|}{ Fit problems } \\
\hline & & \multirow{2}{*}{\multicolumn{2}{|c|}{$\begin{array}{l}\text { Waist size } \\
\text { not found } \\
\text { Size } 20<\end{array}$}} & \multicolumn{4}{|c|}{ Hip size not found } \\
\hline & & & & \multicolumn{2}{|c|}{ <Size 2} & \multicolumn{2}{|c|}{ Size $20<$} \\
\hline Group & $n$ & $n$ & $\%$ & $n$ & $\%$ & $n$ & $\%$ \\
\hline Caucasian people & 840 & 126 & 15.00 & 1 & $0.1 \%$ & 59 & 7.02 \\
\hline African-American & 243 & 53 & 21.81 & N/A & $\mathrm{N} / \mathrm{A}$ & 38 & 15.64 \\
\hline Hispanic & 47 & 4 & 8.51 & $\mathrm{~N} / \mathrm{A}$ & N/A & 0 & 0.00 \\
\hline Mexican-American & 71 & 18 & 25.35 & N/A & N/A & 6 & 8.45 \\
\hline Asian & 71 & 4 & 5.63 & N/A & N/A & 0 & 0.00 \\
\hline Other & 63 & 7 & 11.11 & N/A & N/A & 0 & 0.00 \\
\hline Total & 1335 & 212 & 15.88 & N/A & N/A & 103 & 7.72 \\
\hline
\end{tabular}

Table 8 shows different fit problems of waist height among ethnic groups. As shown in Table 8, Mexican-American (60.56\%), $55.32 \%$ of Hispanics and $56.34 \%$ of Asians have shorter waist height than the standard sizes. On the other hand, $30.04 \%$ of African-American had a longer waist height than provided by current standard sizes. This indicates that statistically different body dimensions among ethnic groups are related to different fit problems with current sizing systems.

Hip sizes seemed to be almost a perfect fit for all ethnic groups because $92.21 \%$ of people found hip sizes as shown in Table 6. For the assessment of fit, the two cases (fit based on hip sizes and fit based on waist sizes) were graphically compared to the ASTM Misses figure type standard sizes. Figures 2 and 3display comparison plots of fit based on waist size (Fig. 2) and on hip size (Fig. 3) respectively.

In the results, when trying to find fit based on waist size, the hips were generally below the fit line in smaller size ranges. In addition, hips were above the fit line in larger size ranges (see Fig. 2). In other words, a consumer who usually wears a small waist size tries on a pair of jeans fitting on waist, but the consumer might find the hip to be too loose on the jeans. If a consumer who usually wore over size 20 tried on a pair of jeans which fit at the waist, but the consumer's hip would not fit appropriately in the jean. Yet, when attempting to find fit based on the hip, the waist sizes were above the fit line overall in all size categories (see Fig. 3). This indicates that neither hip sizes nor waist sizes are applicable for finding a pair of jeans which would fit well.

Table 8 Different fit problems of waist height among ethnic groups

\begin{tabular}{|c|c|c|c|c|c|c|c|}
\hline \multirow{2}{*}{\multicolumn{2}{|c|}{ Ethnicity }} & \multicolumn{6}{|c|}{ Waist height (pants length) not found } \\
\hline & & \multicolumn{2}{|c|}{$<$ size 2} & \multicolumn{2}{|c|}{ size $20<$} & \multicolumn{2}{|c|}{ Total not match } \\
\hline Group & $n$ & $n$ & $\%$ & $n$ & $\%$ & $n$ & $\%$ \\
\hline Caucasian people & 840 & 214 & $25.48 \%$ & 181 & $21.55 \%$ & 395 & 47.02 \\
\hline African-American & 243 & 52 & $21.40 \%$ & 73 & $30.04 \%$ & 125 & 51.44 \\
\hline Hispanic & 47 & 26 & $55.32 \%$ & 4 & $8.51 \%$ & 30 & 63.83 \\
\hline Mexican-American & 71 & 43 & $60.56 \%$ & 7 & $9.86 \%$ & 50 & 70.42 \\
\hline Asian & 71 & 40 & $56.34 \%$ & 5 & $7.04 \%$ & 45 & 63.38 \\
\hline Other & 63 & 29 & $46.03 \%$ & 3 & $4.76 \%$ & 32 & 50.79 \\
\hline Total & 1335 & 404 & $30.26 \%$ & 273 & $20.45 \%$ & 677 & 30.26 \\
\hline
\end{tabular}
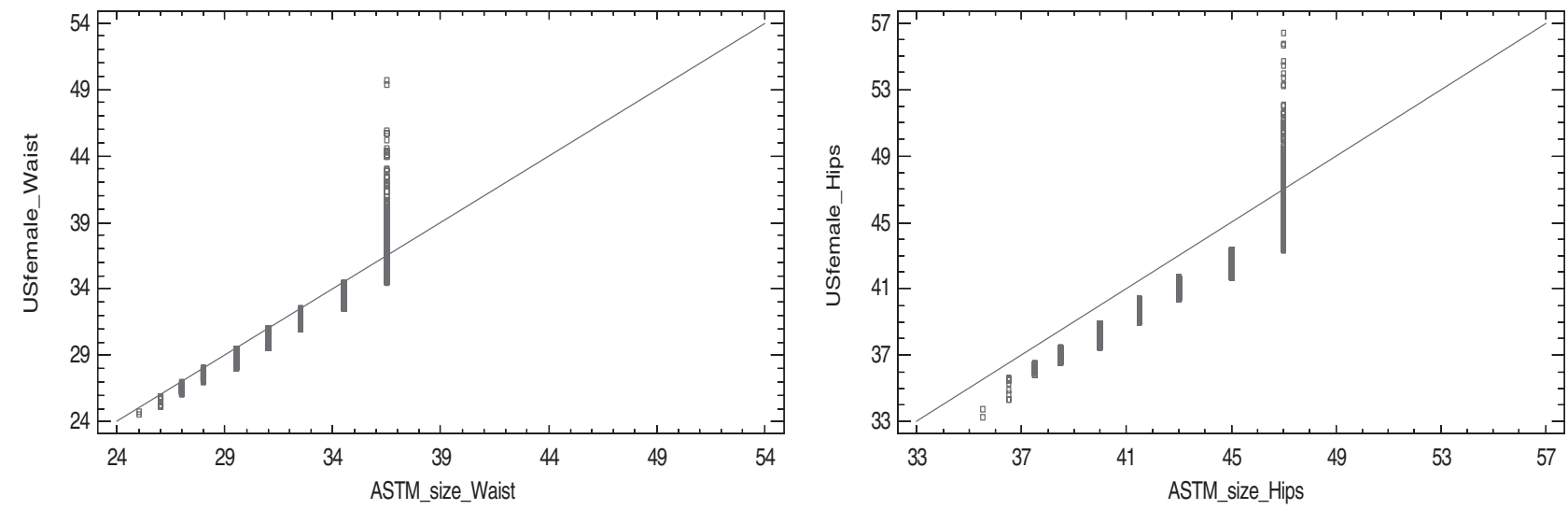

Figure 2 Fit based on waist sizes. 


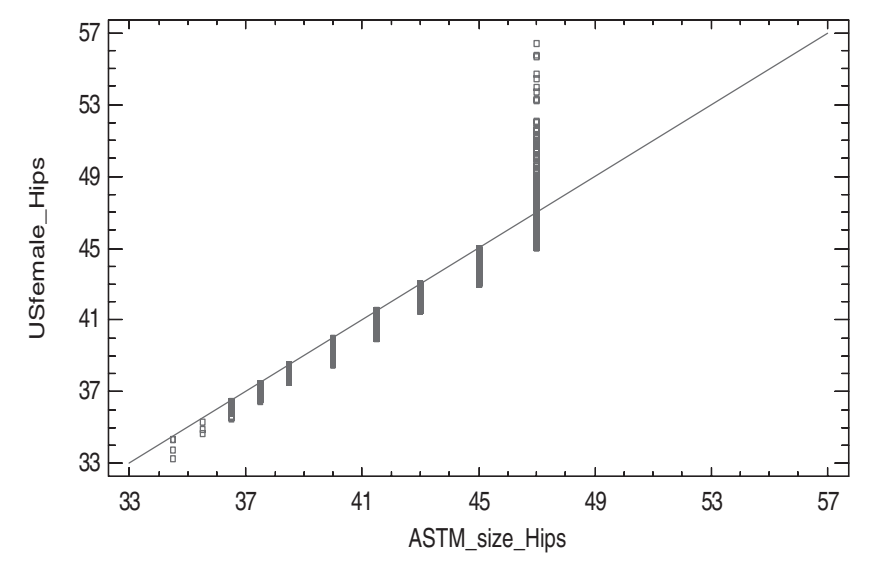

Figure 3 Fit based on hip sizes.

\section{Conclusions and suggestions}

Current jean consumers are diversified in the local US as well as globally. This study revealed a factor that may help define diverse female body shapes in the US population. This study found that diverse ethnic groups had different fit problems, showing the following significant body dimension differences among ethnic groups:

- Caucasian people and African-Americans had similar waist heights (usually pants length) and crotch heights (inseam) showing taller heights than other groups. However, the Caucasian people's thigh girth average was much smaller than the AfricanAmerican's.

- African-American had a large lower body dimensions, showing larger thigh and hips and waist than other groups' while Asians and Hispanics show smaller body dimensions among the groups.

- The Asian, Mexican-American and Hispanic had similar waist heights and crotch heights, showing shorter heights than other groups.

- The Mexican-Americans and Hispanics had a statistically different lower body dimensions in a Misses figure body type size category, showing Mexican-Americans have a bigger waist than other ethnic groups while Hispanics had a smaller waist similar to Asians.

- Asian and Hispanics in a Misses figure body type size category had very similar lower body dimensions, showing smaller hips and waist and shorter waist heights.

Even within the same figure type size ranges, a variety of body dimensions existed in each ethnic group. According to the fit problem assessment in this study, consumers within the same body figure type size category would not be able to find the right fit of pants/jeans within the current sizing system. When each consumer found a pair of jeans based on the three cases: (1) waist sizes; (2) hip sizes; and (3) waist height (pants length), the most largest fit problem $(49.29 \%)$ was found in waist height (pants length) because most women's apparel companies provide little or no choice of pants lengths, unlike men's apparel companies who offer various pants lengths within a waist size. This indicates that a half of all female consumers can not find the right pants length and must pay extra cost for altering pants length.

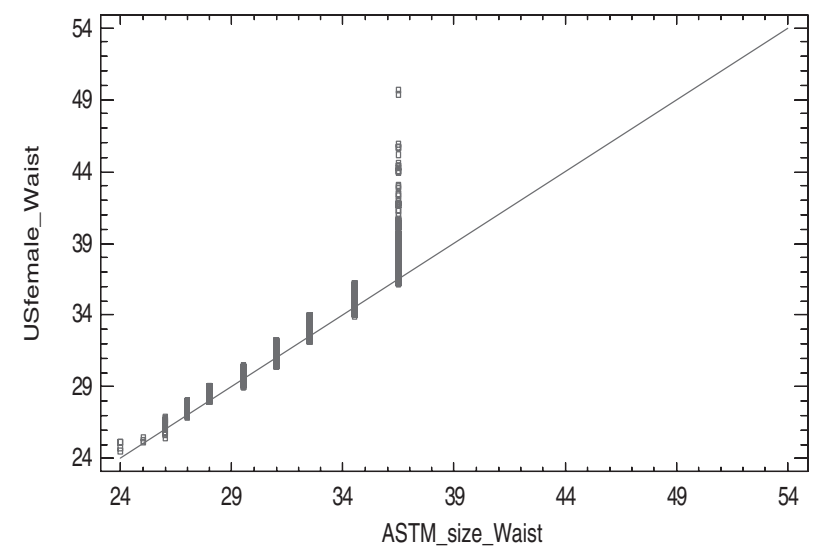

Each ethnic group showed different fit problems within the current standard sizing system. African-Americans showed fit problems in waist and hips because of larger waist and hips than the defined waist and hip sizes. Mexican-Americans showed fit problems in hips because of larger hips than the defined hip sizes. Mexican-American, Hispanics and Asians had fit problems in waist height (pants length) because of the need for a shorter length than the defined pants length sizes, while African-Americans showed fit problems in waist height because of being taller than the defined pants length sizes. These unique fit problems in each ethnic group are clearly explained with the statistically different body dimensions among ethnic groups that should have been considered for a sizing system.

Compared with waist sizes, hip sizes seemed to show better matches. However, according to the plot comparisons of fit with hips vs. waist, hip was not a better fit match for finding a pair of jean. For instance, when hip was the constraint for the fit, the waist was above the fit line overall in all sizes. Neither hip sizes nor waist sizes were applicable for diverse consumers. Just a few inch differences in hip measurement could cause a very uncomfortable fit of the tight jeans market for consumers.

Therefore, apparel manufacturers must be aware of differences in ethnicity to provide better quality of fit and the right sizes for diverse consumers in the international market, as well as the local US market. Each ethnic group has unique body shapes as well as different fit problems and preferences, so it is necessary to offer a variety of fits to ensure that the consumer will be able to find one that works for them.

The current sizing systems have not been developed for the diverse consumers. Although it is difficult for apparel manufacturers to set size ranges and grading rules to fit every figure. It is important, however, for organizations to establish standards with awareness of the demographic factor of ethnicity that has different body shapes and dimensions. Thus, sizing systems should be modified to be able to apply for the current consumers. Further study should be carried out for defining body shapes with understanding shape differences among ethnic groups.

\section{Acknowledgement}

$[\mathrm{TC}]^{2}$ supported our research by providing SizeUSA data. 


\section{References}

Alexander, M., Connell, L.J. \& Ulrich, P.V. (2004) Using threedimensional body scan data for body shape and body build analysis. International Textile and Apparel Association Annual Conference Proceedings, (61), 5-6.

Allen, R. \& Huffman, M. (2005) An analysis of the US bottom weights market: production, consumption, and denim. Journal of Textile and Apparel, Technology and Management, 4, 1-11.

Anderson, L., Brannon, E., Ulrich, P., Jenkins, A., Early, J., Grasso, M. \& Gray, S. (1998) Understanding fitting preferences of female consumers: development an expert system to enhance accurate sizing selection. National Textile Center Project, I98-A8/1.

Ashdown, S.P. (1997) An investigation of the structure of sizing systems. International Journal of Clothing Science and Technology, 10, 324-341.

ASTM (2004) ASTM D5585 adult female misses figure type sizes 2-20. American Society of Testing Material International Standard, 7(2), 1-4.

Brown, P. \& Rice, J. (2001) Ready-to-Wear Apparel Analysis, 3rd edn. Prentice Hall, Upper Saddle River, NJ.

Connell, L., Ulrich, P., Knox, A., Hutton, G., Woronka, D. \& Ashdown, S. (2003) Body scan analysis for fit models based on body shape and posture analysis, National Textile Center Annual Report, NTC project S01-AC27.

Cotton Inc. (2005) Denim around the globe. Lifestyle Monitor Trend Magazines: Denim Issue. [WWW document]. URL http://www.cottoninc. com/LifestyleMonitor/LSMDenim2005 (accessed on 12 September 2005).

Fu, M. (2004) Pattern development for overweight and obese women: integrating body shape analysis with an understanding of preferences and needs. Dissertation. Auburn University.

Glock, R. \& Kunz, G. (2005) Apparel Manufacturing: Sewn Product Analysis, 4th edn. Pearson Prentice Hall, Upper Saddle River, NJ.

Goldsberry, E., Soyeon, S. \& Reich, N. (1996) Women 55 years and older: part II. Overall satisfaction and dissatisfaction with the fit of ready-towear. Clothing and Textiles Research Journal, 14, 121-132.

Gordon, C., Churchill, T., Clauser, C., Bradtmiller, B. \& McConville, J. (1988) Anthropometric Survey of the U.S. Army Natick R\&D Center, Technical Report, Natick/TR-89/044. US Army Natick R\&D Center, Natick, MA.

Hwang, S. \& Istook, C. (2001) Body measurement terminology used in the apparel industry. Proceedings of the 2001 Seoul KSCT/ITAA Joint World Conference, 91, 24.

Intellifit Corp (2003) Pattern optimization. [WWW document]. URL http://intellifit.com/patopt.htm (accessed on 15 December 2003).

Istook, C. (2006) Initial analysis of SizeUSA data for development of new sizing systems for the U.S. female population. Proceedings of the International Textile and Apparel Association Annual Conference in San Antonio, TX, 1-6 November 2006.

Jo, L., Ulrich, Woronka, Hutton, \& Ashdown, S. (2003) Body scan analysis for fit models based on body shape and posture analysis. National Textile Center, S01-AC27.
Kim, E. \& Kim, Y. (2005) The effects of ethnicity and gender on teens' mall shopping motivations. Clothing and Textiles Research Journal, 23, 65-77.

LaBat, L. \& DeLong, R. (1990) Body cathexis and satisfaction with fit of apparel. Clothing and Textiles Research Journal, 8, 43-48.

Lands' End Inc. (2006) Custom Clothing. [WWW document]. URL http://www.landsend.com/cd/index/fp/0,49299,00.html?sid= 8660169403066184060 (accessed on 14 January 2006).

Mellian, S., Ervin, C. \& Robinette, K. (1990) Sizing Evaluation of Navy Women's Uniforms, Navy Clothing and Textile Research Facility Technical Report, No. NCTRF 182. Navy and Clothing Textile Research Facility, Natick, MA.

Nachman, B. (2005) Most wanted woman. The Journal News, Westchester, NY.

Pine, J. (1993) Mass Customization. Harvard Business School Press, Boston, MA.

Robinette, K., Mellian, S. \& Ervin, C. (1990) Development of sizing systems for navy women's uniforms. Navy Clothing and Textile Research Facility Technical Report, No. NCTRF 182.

Simmons, K. (2002) Body shape analysis using three-dimensional body scanning technology. Unpublished Doctoral Dissertation. North Carolina State University, Raleigh, NC.

Simmons, K.P., Istook, C. \& Devarajan, P. (2004) 'Female Figure Identification Technique (FFIT)' for apparel, Part II: Development of shape sorting software. Journal of Textile and Apparel, Technology and Management, 4, 1-15. [WWW document]. URL http://www.tx.ncsu.edu/ jtatm/volume4issue1/articles/Istook/Istook_full_107_04.pdf (accessed on 12 December 2004).

Telmat Industrie (2002) Instant 3D Capture \& Automated Body Measurement. [WWW document]. URL http://www.symcad.com/eng/index.htm (accessed on 16 March 2002).

Tigert, D., Reynolds, C., Cotter, T. \& Arnold, S. (1996) The 1996 Chicago female research project. Chain Store Age, 72, 5-31.

US Department of Commerce Bureau of the Census (1998) Census and you. U.S. Department of Commerce Bureau of the Census, 33, 6. [WWW document]. URL http://www.census.gov/prod/3/98pubs/cay9809.pdf (accessed on 1 October 2005).

US Census Bureau (2001) National population projections. Population Division and Housing and Household Economic Statistics Division, January 2001. [WWW document]. URL http://www.census.gov/ population/www/pop-profile/natproj.html (accessed on 1 October 2005).

Urban Institute Immigration Studies Program (2002) The dispersal of immigrants in the 1990s. Urban Institute Immigration Studies Program, Brief no. 2. [WWW document]. URL http://www.urban.org/ UploadedPDF/410589_DispersalofImmigrants.pdf (accessed on 1 October 2005).

Vrontis, D. \& Vronti, P. (2004) Levi Strauss: an international marketing investigation. Journal of Fashion Marketing and Management, 8, 389398. 
Copyright of International Journal of Consumer Studies is the property of Blackwell Publishing Limited and its content may not be copied or emailed to multiple sites or posted to a listserv without the copyright holder's express written permission. However, users may print, download, or email articles for individual use. 